\title{
The role of lubricant feed temperature on the performance of twin groove journal bearings: an experimental study
}

\author{
Francisco P. Brito*, \\ António Sousa Miranda and \\ José Carlos Pimenta Claro
}

Centro de Tecnologias Mecânicas e de Materiais (CT2M),

Universidade do Minho, Campus de Azurém,

4800-058 Guimarães, Portugal

Fax: +351-256685323

E-mail: francisco@dem.uminho.pt

E-mail: asm@dem.uminho.pt

E-mail: jcpclaro@dem.uminho.pt

*Corresponding author

\section{Michel Fillon}

Institut Pprime, CNRS - Université de Poitiers - ENSMA, Département Génie Mécanique et Systèmes Complexes, UPR 3346, SP2MI - Téléport 2 - 11, Boulevard Marie et Pierre Curie, BP 30179, F86962 Futuroscope Chasseneuil, France

Fax: +33-549496504

E-mail: michel.fillon@univ-poitiers.fr

\begin{abstract}
An experimental assessment of the influence of lubricant feed temperature $\left(T_{f}\right)$ on the behaviour of twin groove hydrodynamic journal bearings has been undertaken. Several loads, shaft speeds and bearing geometries were tested under constant lubricant feed pressure $\left(p_{f}\right)$, while $T_{f}$ took four different values between $29^{\circ} \mathrm{C}$ and $58^{\circ} \mathrm{C}$.

It was found that the increase of $T_{f}$ has an effect in bearing performance which is analogous in many ways to the effect of the increase in eccentricity: increase in lubricant flow rate (especially in the low eccentricity range), in outlet temperature (Tout) and in maximum bush temperature (Tmax). Nevertheless, the latter increase was lower than the corresponding increase in $T_{f}$. Also, in the high eccentricity range the increase in flow rate due to the increase of $T_{f}$ could be deceiving in the sense that the additional flow was supplied mainly to the inactive region of the bearing (the unloaded land of the bearing).
\end{abstract}

Keywords: hydrodynamic lubrication; journal bearings; supply conditions; feed conditions; thermal behaviour; feed temperature; $T_{f}$; supply temperature.

Reference to this paper should be made as follows: Brito, F.P., Miranda, A.S., Claro, J.C.P. and Fillon, M. (2011) 'The role of lubricant feed temperature on the performance of twin groove journal bearings: an experimental study', Int. J. Surface Science and Engineering, Vol. 5, No. 4, pp.286-299. 
Biographical notes: Francisco P. Brito is Invited Professor in Mechanical Engineering at ISEP, Porto, Portugal, and Post-Doctoral Researcher in systems for electric vehicles and thermodynamics at the MIT Portugal programme at the University of Minho (UM), Guimarães, Portugal. He received his PhD in Hydrodynamic Lubrication at UM in 2009. He has made theoretical and experimental work on hydrodynamic journal bearings at UM and at the University of Poitiers (P'Institute - UPR 3346), France, He has co-authored around 15 articles in scientific journals and conference proceedings in the areas of lubrication, applied thermodynamics and automotive engineering.

António Sousa Miranda is a Professor in Mechanical Engineering at the University of Minho, Portugal. He has been Vice-Dean of the School of Engineering (1994-1998), Director of the Mechanical Engineering Department (1999-2002), and Coordinator of the Centre for Mechanics and Materials Technologies (2007-2010), a research unit supported by the (national) Science and Technology Foundation. His research interests lie in the area of tribology, being mainly related to wear of materials and hydrodynamic lubrication. He is a member of the scientific committee of the journal Mecânica Experimental and of the editorial board of the International Journal of Surface Science and Engineering

José Carlos Pimenta Claro is an Associate Professor of the Department of Mechanical Engineering, University of Minho, since 2001. He is also the Coordinator of the research group in Dynamics of Mechanical Systems of the Centre for Mechanical Technologies and Materials (CT2M), Portuguese Foundation for Science and Technology, since 2007. For the last three years, he has produced two books, five international publications, ten international communications, one national patent, several reviews of scientific international publications and several reviews of scientific international communications. Further, he is a member of the advisor board of the Georgian National Science Foundation.

Michel Fillon is a CNRS Director of Research at the University of Poitiers. He works in the field of tribology and lubrication. His interests are both experimental and theoretical investigations of hydrodynamic journal and thrust bearings. Member of ASME and STLE since 1994, he became STLE Fellow in 2010. From 2006 to 2008, he was the Chair of Research Committee of ASME Tribology Division and has been an associate editor of ASME Journal of Tribology. He is a board member of Journal of Engineering Tribology and of International Journal of Surface Science and Engineering. He organises the EDF/Prime Poitiers Workshops since 2002.

This paper is a revised and expanded version of a paper entitled 'The role of lubricant supply temperature on the performance of twin groove journal bearings: an experimental study' presented at Ibertrib 2009, 5th Iberian Congress on Tribology, Coimbra, Portugal, 17-18 June 2009.

\section{Introduction}

Hydrodynamic journal bearings are frequently used in the support of high speed, heavily loaded rotating shafts. Frequently, the lubricant is supplied at a prescribed pressure and temperature through one or two axial grooves. The lubricant feed temperature $\left(T_{f}\right)$, is a factor which deeply affects the performance of these machine elements.

Lubricant viscosity, which strongly depends on local temperature, is the parameter responsible for hydrodynamic pressure generation within the fluid. Therefore, the 
variation of $T_{f}$ is likely to exert a strong influence not only on the temperature field, the power loss and the flow patterns, but also on the bearing eccentricity and ultimately on the load carrying capacity of the bearing. It is true that feeding the lubricant at low $T_{f}$ tends to maximise bearing cooling efficiency and load capacity even if it is at the expense of a slightly higher power loss caused by the added drag. However, in the absence of an efficient oil cooling system, it is not always possible to keep $T_{f}$ as low as desired, especially under severe operating conditions where large amounts of heat are generated by viscous dissipation. Under these conditions the high $T_{f}$ values raise the seizure risk not only because dangerously high eccentricities might be induced, but also because thermal distortion will further facilitate localised contact due to the thermal crowning of surfaces. A loss in lubricant viscosity also tends to reduce damping, promoting an unstable operation.

A suitable knowledge of the actual influence of $T_{f}$ on bearing performance would therefore be of great help. Some previous theoretical and experimental works have addressed this issue, although with bearing types which were different from those tested in the present work. Mitsui et al. (1983) and Costa et al. (2003a, 2003b) focused their studies on single groove journal bearings, while Ma and Taylor (1995) studied the elliptical bearing. Recent work by the authors on a different test rig has already started to address the lack of knowledge on lubricant supply conditions such as lubricant feed pressure $\left(p_{f}\right)$ and $T_{f}$ (Brito et al., 2006, 2007a). However, the lack of knowledge concerning the proportion of the flow fed through each groove somewhat limited the discussion. One of the main contributions of the tests carried out in the rig of Minho University is the ability to perform an accurate flow measurement of the individual flow rates entering each one of the grooves. This knowledge has proved to be a major contribution for the understanding of twin groove journal bearing behaviour.

\section{Test rig}

A schematic view of the experimental test rig existing in the Tribology Laboratory of the University of Minho is represented in Figure 1. Although this apparatus has already been used on several works (Claro and Miranda, 1993; Costa et al., 2003b) several of its capabilities, especially those related to data acquisition, signal treatment, flow rate measurement and $T_{f}$ regulation, were significantly improved for the present work.

The geometric parameters, operating and supply conditions, as well as lubricant properties, are presented in Table 1.

The rig allows the regulation of rotational speed, applied load, oil $p_{f}$ and $T_{f}$. The measured performance parameters were the temperature at the oil-bush interface, the oil outlet temperature, the oil flow rate at each groove, the total oil flow rate, and the shaft locus.

The shaft was driven by a $0.95 \mathrm{~kW}$ variable speed motor via a transmission belt. The speed was regulated through an inverter drive and kept within a range of $\pm 10 \mathrm{rpm}$ of the nominal speed. The shaft, made of X22-CrNi17 stainless steel, was rigidly mounted on by two precision preloaded conical rolling bearings that assured an adequate stiffness to the system. The bush was made of RG5G-CuSn $5 \mathrm{ZnPb}$ bronze. The bush diameter, the shaft diameter and cylindricity were measured using a 'Mitutoyo BHN706' coordinate measuring machine with a resolution of $0.1 \mu \mathrm{m}$. The oil used was ISO VG 32 (Galp Hidrolep 32 - see Table 1 for details). 
Figure 1 Schematic overview of the test rig (see online version for colours)

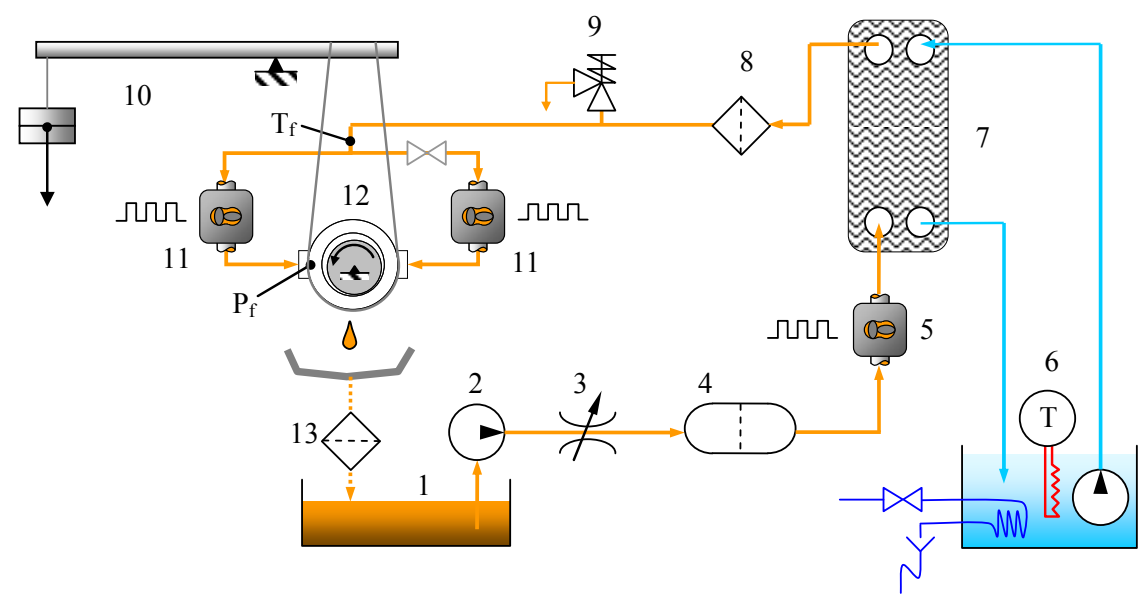

Notes: $1=$ oil tank; $2=$ gear pump; $3=$ flow regulation valve; $4=$ pulse damper;

$5=$ electric pulse gear flow metre (total flow rate); $6=$ temperature controlled water bath with outer circulation; $7=$ plate heat exchanger; $8=$ filter; $9=$ relief valve;

$10=$ loading system; 11 = electric pulse gear flow metres; 12 = instrumented bearing system; 13 = filter

Table 1 Main bearing characteristics, lubricant properties and operating conditions

\begin{tabular}{lcccc}
\hline Parameters & \multicolumn{2}{c}{ Units } & Bearing B2V1 & Bearing B3V1 \\
\hline Geometrical bearing characteristics & & & & \\
- Inner bush diameter (nominal) & $d$ & $\mathrm{~mm}$ & 50 & 50 \\
- Outer bush diameter & $D$ & $\mathrm{~mm}$ & 100 & 100 \\
- Bush length/diameter ratio & $b / d$ & & 0.8 & 0.5 \\
- Groove length/bush length ratio & $a / b$ & & 0.8 & 0.8 \\
- Groove width/diameter & $w / d$ & & 0.2 & 0.2 \\
- Bearing diametral clearance $\left(\right.$ at $\left.20^{\circ} \mathrm{C}\right)$ & $C_{d}$ & $\mu \mathrm{m}$ & 86 & 54 \\
Oil properties & & & $\mathrm{ISO} \mathrm{VG} 32$ & $\mathrm{ISO} \mathrm{VG} 32$ \\
- Dynamic viscosity at $30^{\circ} \mathrm{C}$ & $\mu_{30}$ & $\mathrm{~Pa}, \mathrm{~s}$ & 0.0467 & 0.0467 \\
- Dynamic viscosity at $75^{\circ} \mathrm{C}$ & $\mu_{75}$ & $\mathrm{~Pa}, \mathrm{~s}$ & 0.0083 & 0.0083 \\
- Specific heat & $C p$ & & 1,943 & 1,943 \\
- Specific mass & $\rho$ & $\mathrm{Kg} / \mathrm{m}^{3}$ & 875 & 875 \\
- Thermal conductivity & $k$ & $\mathrm{~W} / \mathrm{mK}$ & 0.13 & 0.13 \\
Operating conditions & & & & \\
- Rotational speed & $N$ & $\mathrm{rpm}$ & 2,$000 ; 4,000$ & 4,000 \\
- Applied load & $W$ & $\mathrm{kN}$ & $0.4-5$ & $0.4-5$ \\
Supply conditions & & & & \\
- Oil supply pressure & $P r$ & $\mathrm{kPa}$ & 100 & 100 \\
- Oil supply temperature & ${ }^{\circ} \mathrm{C}$ & $29.5 ; 39 ; 48.5 ; 58$ & $29 ; 39 ; 48.5 ; 58$ \\
\hline
\end{tabular}


The loading arrangement relies on a cantilever system on which dead weights are applied. The cantilever acts on the bush body through a closed-loop steel wire. The loading system was calibrated using a high precision load cell with an error of less than $\pm 0.5 \mathrm{~N}$.

The $p_{f}$ was regulated by a restrictor valve and monitored by pressure transducers located at the interior of each groove. $p_{f}$ was kept within an interval of variation of $\pm 0.004 \mathrm{MPa}$.

The $T_{f}$ was regulated via a thermostatic bath with outer circulation passing through a plate heat exchanger in order to heat the oil that was being supplied to the bearing. The temperature of the bath was regulated so that $T_{f}$ was kept within a range of $\pm 0.4^{\circ} \mathrm{C}$ from the set point. $T_{f}$ was monitored by three thermocouples, one located in the main feeding pipe, just upstream of the point where the flow is separated in two branches to feed each groove and two other thermocouples, one on each groove, just before the groove entrance.

The measurements were always made under a steady-state regime. In order to achieve this, start-up times were set for thermal stabilisation. Between tests, parameters such as temperature and flow rate were monitored until stabilisation was achieved.

The oil flow was measured by three gear flow metres (repeatability $0.03 \%$ ), suitable for low flow rate measurements, linked to the data acquisition system. One flow metre was attached to the main feed line, while the other two were located in each branch in order to measure partial flow rates. To ensure accurate flow rates, measurements were performed during 35 seconds. The difference between the total flow rate and the sum of the partial flow rates was below $1.5 \%$ in most of the cases.

The temperature field was monitored by type $\mathrm{K}$ thermocouples attached to a data acquisition system. The repeatability of the measured values was within $\pm 1^{\circ} \mathrm{C}$. The temperature at the oil-bush interface was measured at the locations depicted in Figure 2. The thermocouples were placed inside fully drilled holes, flush with the inner bush surface. Another set of thermocouples was positioned so as to measure the oil outlet temperature and the environment temperature.

Figure 2 Angular location of the thermocouples at the inner surface of the bush (unwrapped view) (see online version for colours)
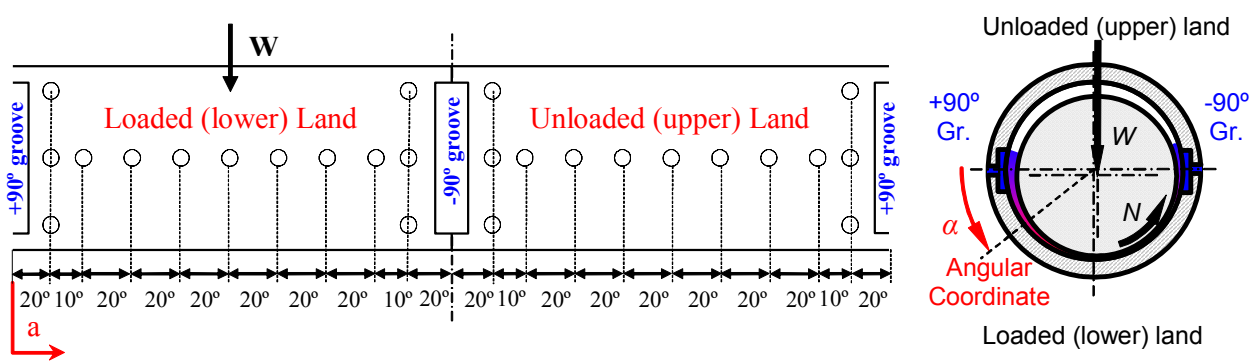

The relative shaft position was obtained with the help of two pairs of Eddy current proximity probes located at $\pm 45^{\circ}$ to the load line, on both sides of the bearing. The system was calibrated, and sensitivities around $7 \mathrm{mV} / \mu \mathrm{m}$ were obtained. The accuracy of the measurements was found to be strongly affected by thermal and elastic deformations of the various components. Estimations were performed in order to compensate these deformations. Additionally, some reference tests had to be used, with the locus of the 
shaft centre being estimated in reference to tests where the absolute position of the shaft has been obtained from a theoretical model presented by Costa et al. (2003a) adapted for twin groove bearings. For each $T_{f}$ a specific reference test has been adopted.

\section{Results and discussion}

\subsection{Shaft locus}

Figure 3 shows the influence of the $T_{f}$ on the eccentricity ratio for $4,000 \mathrm{rpm}$ tests of two different bearing geometries. It can be seen that $\varepsilon$ increases with the increase of $T_{f}$. This happens mainly due to the loss of viscosity suffered by the hotter lubricant, which decreases the load carrying capacity of the bearing.

Figure 3 Influence of lubricant $T_{f}$ on the eccentricity ratio of (a) bearing B3V1 (b) bearing B2V1 $\left(\mathrm{N}=4,000 \mathrm{rpm}, p_{f}=100 \mathrm{kPa}\right.$ ) (see online version for colours)

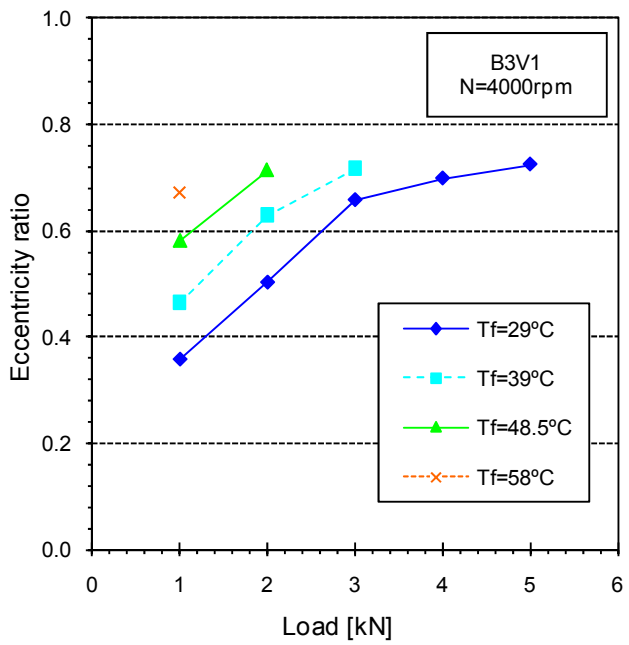

(a)

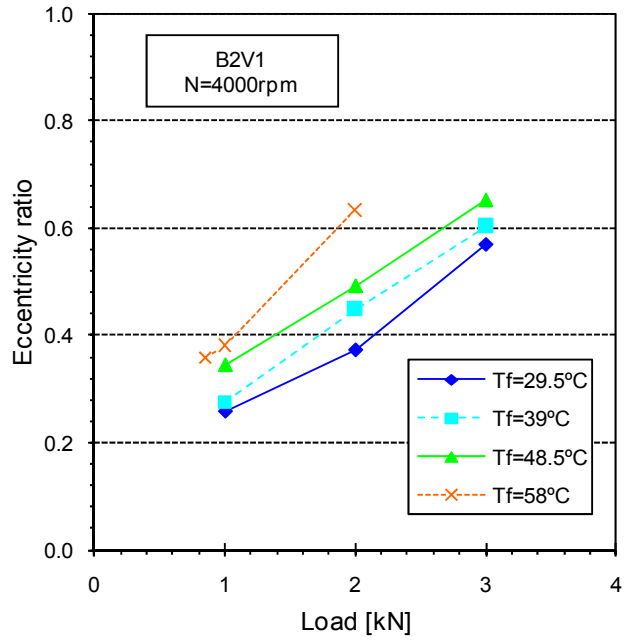

(b)

Note: Due to measuring uncertainties, these values should be regarded mainly as indicative.

For the same working conditions, bearing B2V1 displays a lower eccentricity than bearing B3V1. Although comparisons between bearings with dissimilar clearances should be made with caution, it is clear in this case that the notable differences in eccentricity between the two cases are mainly due to the totally different specific loads present (the two bearings have dissimilar lengths - they display b/d ratios of 0.8 and 0.5 , respectively).

\subsection{Lubricant flow rate}

Flow rate results (total flow rate and partial flow rates at each groove) corresponding to several working conditions and $T_{f}$ values are presented in Figures 4 to 6 . 
Figure 4 Influence of $T_{f}$ on (a) total flow rate (b) $+90^{\circ}$ groove flow rate (c) $-90^{\circ}$ groove flow rate (bearing $\mathrm{B} 3 \mathrm{~V} 1, \mathrm{~N}=4,000 \mathrm{rpm}, p_{f}=100 \mathrm{kPa}$ ) (see online version for colours)

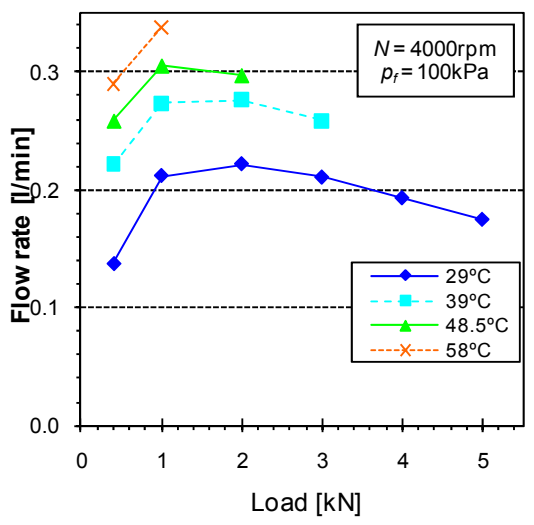

(a)

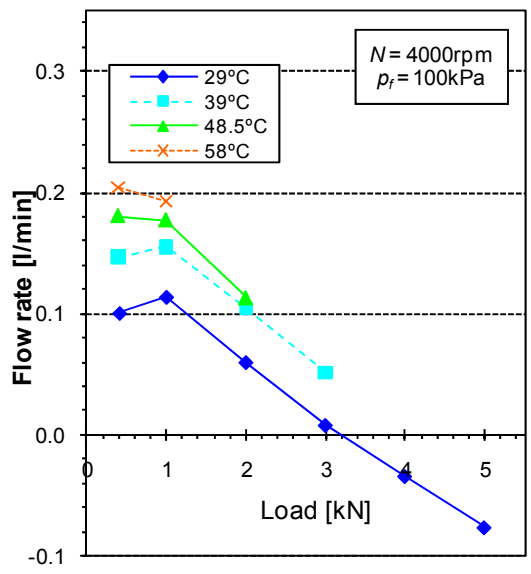

(b)

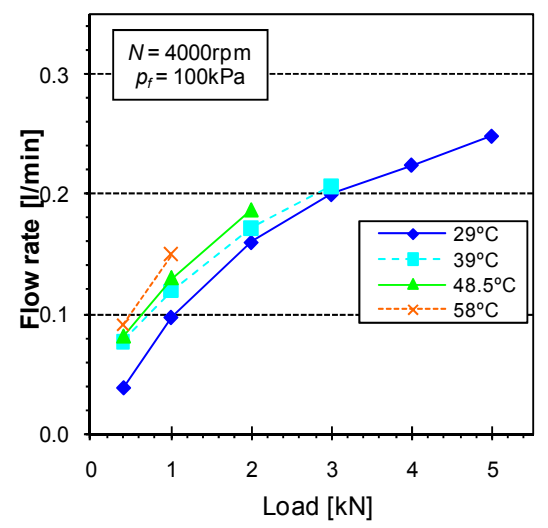

(c)

For the $4 \mathrm{kN}$ and $5 \mathrm{kN}$ tests, it is interesting to note the occurrence of negative flow rate at the groove located at the convergent portion of the film [the $+90^{\circ}$ groove - see Figure 4(b)]. This rarely reported phenomenon, in which the lubricant flows out of the bearing gap through the groove instead of flowing into it, occurs when the hydrodynamic pressure field at the vicinity of the groove exceeds the $p_{f}$. This phenomenon has been first described elsewhere (Brito et al., 2007b, 2008).

It can be seen that the total flow rate tends to increase with increasing $T_{f}$, especially in the lower range of applied load. For instance, for the lightest load tested $(0.4 \mathrm{kN})$, the total flow rate and the flow rate at each groove of bearing $\mathrm{B} 3 \mathrm{~V} 1$ approximately doubled as $T_{f}$ changed from $29^{\circ}$ to $58^{\circ} \mathrm{C}$ [see Figure 4(a)]. The reason for this could be explained as follows. On one hand, the increase of $T_{f}$ yields a decrease in lubricant viscosity which promotes the oil flow. On the other hand, by inspecting the eccentricity chart displayed in Figure 3 , it can be seen that the increase of $T_{f}$ brought an increase in shaft eccentricity. It is a known fact that within the lower eccentricity range the increase of $\varepsilon$ is normally associated with an increase in total flow rate (Brito et al., 2007a). 
Figure 5 Influence of $T_{f}$ on (a) total flow rate (b) $+90^{\circ}$ groove flow rate (c) $-90^{\circ}$ groove flow rate (bearing $\mathrm{B} 2 \mathrm{~V} 1, \mathrm{~N}=2,000 \mathrm{rpm}, p_{f}=100 \mathrm{kPa}$ ) (see online version for colours)

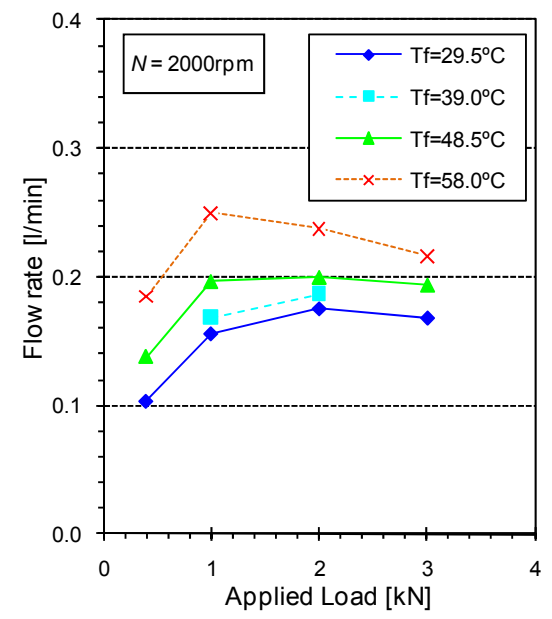

(a)

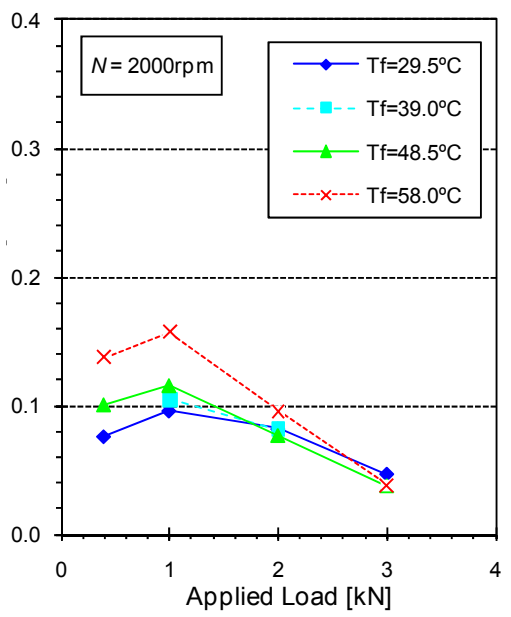

(b)

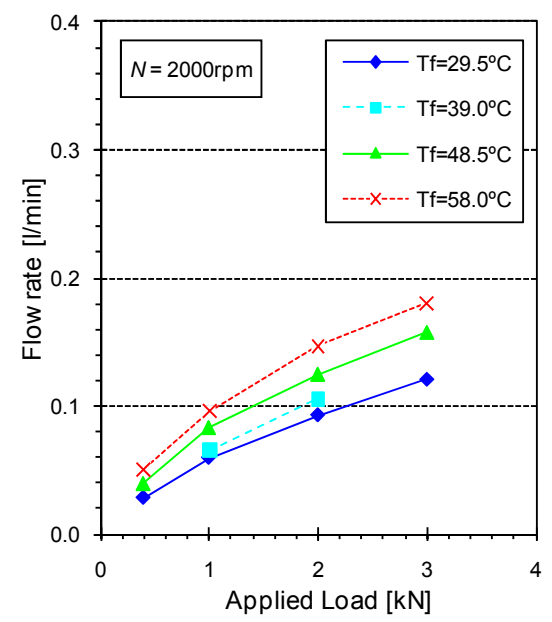

(c)

For higher loads, however, the increase of the total flow rate with increasing $T_{f}$ tends to be mitigated, with the flow rate curves for each $T_{f}$ getting closer to each other. Inclusively, the increase of $T_{f}$ lead in some cases to the decrease of the flow rate at the $+90^{\circ}$ groove, as Figures 5(b) and 5(b) depict. This occurred with combinations of high $T_{f}$ and high load, which corresponded to the tests with the highest eccentricity, as seen in Figure 3(b). Again, this is in agreement with what was already observed in previous works (Brito et al., 2007b), that within the high eccentricity range, the $+90^{\circ}$ groove flow rate tends to decrease with increasing eccentricity. Therefore, it may be affirmed that $T_{f}$ has an influence on flow rate which is analogous to that of load, in the sense that both influence eccentricity in the same way. 
Increasing $T_{f}$ also causes dissimilar thermal expansions of the bush and shaft that increase the effective clearance of the bearing. This should also contribute to the increase of total flow rate with increasing $T_{f}$.

Unfortunately, there are no results available in order to assess the influence of $T_{f}$ in the negative range of the +90 groove flow rate. However, by observing the trends of the curves in Figure 5(b) and Figure 6(b), it can be advanced that the increase of $T_{f}$ should actually lower the critical load at which the negative flow rate phenomenon starts occurring.

Figure 6 Influence of $T_{f}$ on (a) total flow rate (b) $+90^{\circ}$ groove flow rate (c) $-90^{\circ}$ groove flow rate (bearing $\mathrm{B} 2 \mathrm{~V} 1, \mathrm{~N}=4,000 \mathrm{rpm}, p_{f}=100 \mathrm{kPa}$ ) (see online version for colours)

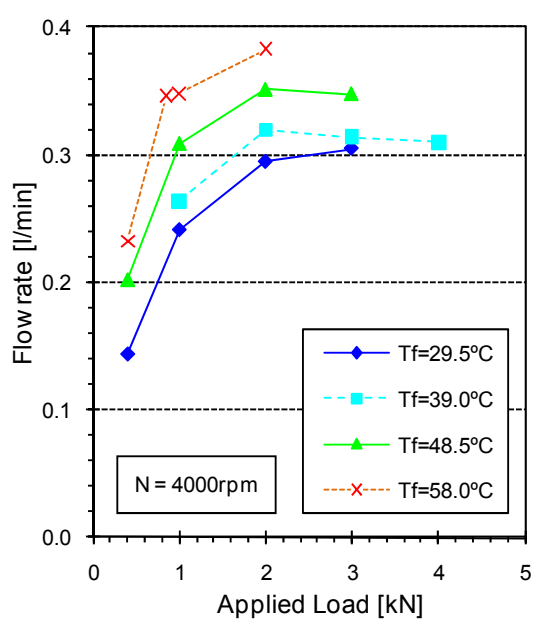

(a)

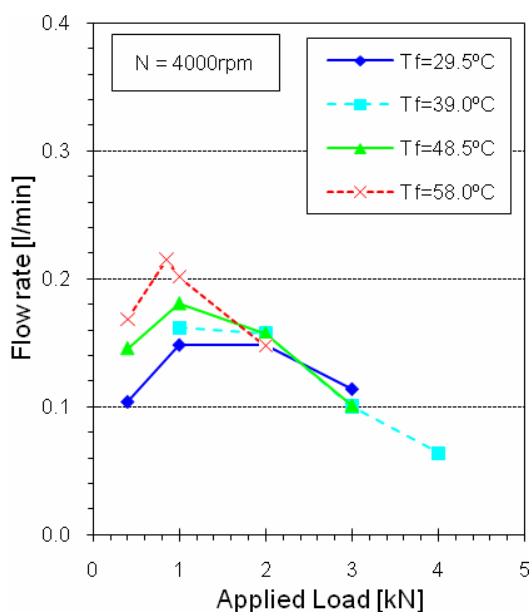

(b)

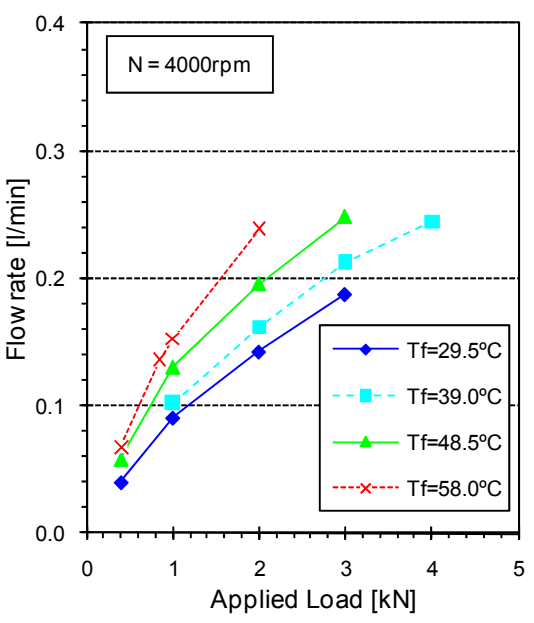

(c) 
Figure 7 Influence of lubricant $T_{f}$ on the temperature profile at midplane of the inner bush surface for (a) $\mathrm{W}=0.4 \mathrm{kN}$ (b) $1 \mathrm{kN}$ (c) $2 \mathrm{kN}$ (bearing B3V1, N = 4,000 rpm, $p_{f}=100 \mathrm{kPa}$ ) (see online version for colours)

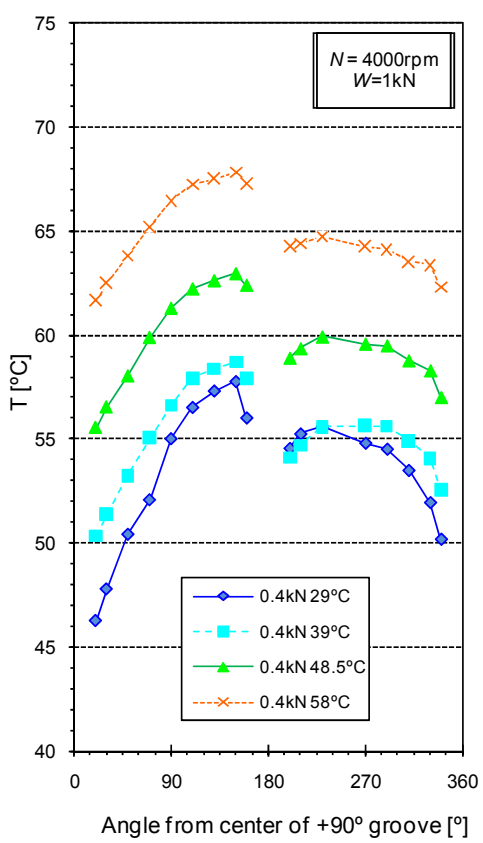

(a)

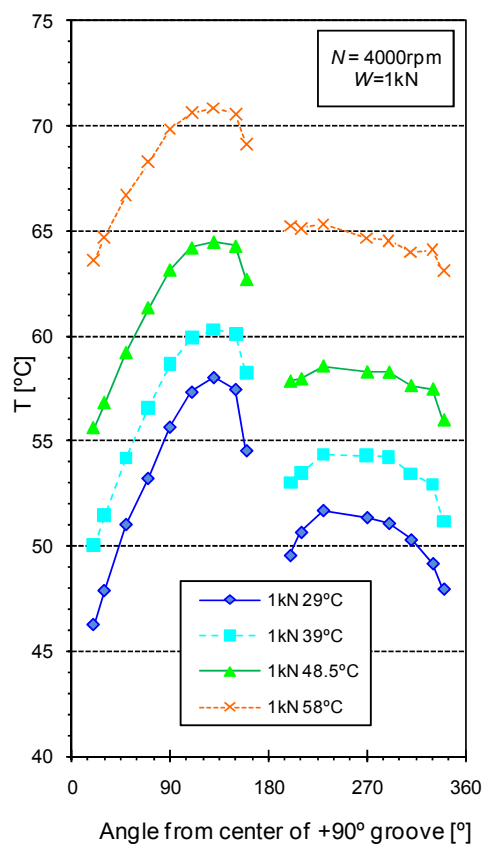

(b)

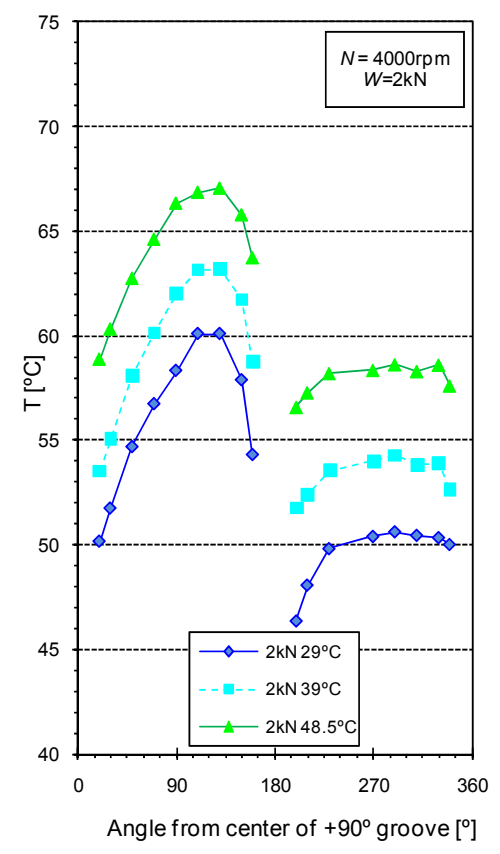

(c) 


\subsection{Temperature field}

Figure 7 displays the temperature profiles at the midplane of the inner bush surface of bearing B3V1 for three different values of load $(0.4 \mathrm{kN}, 1 \mathrm{kN}$ and $2 \mathrm{kN})$ and four different values of $T_{f}\left(29^{\circ} \mathrm{C}, 39^{\circ} \mathrm{C}, 48.5^{\circ} \mathrm{C}, 58^{\circ} \mathrm{C}\right)$. The profiles corresponding to the different values of $T_{f}$ although very different in level are similar in trend. Some differences may be observed at the vicinity of grooves. The lower is $T_{f}$, the stronger is the temperature depression observed around these regions, both before and after the grooves. This causes the temperature span of each curve to decrease as $T_{f}$ increases.

Figure 8(a), which summarises the maximum bush temperature for each test, shows that the increase of Tmax is smaller than the corresponding increase of $T_{f}$. The same applies to the lubricant outlet temperature, as displayed in Figure 8(b).

Figure 8 Influence of lubricant $T_{f}$ on (a) bush maximum temperature (b) lubricant outlet temperature (bearing B3V1, $\mathrm{N}=4,000 \mathrm{rpm}, p_{f}=100 \mathrm{kPa}$ ) (see online version for colours)

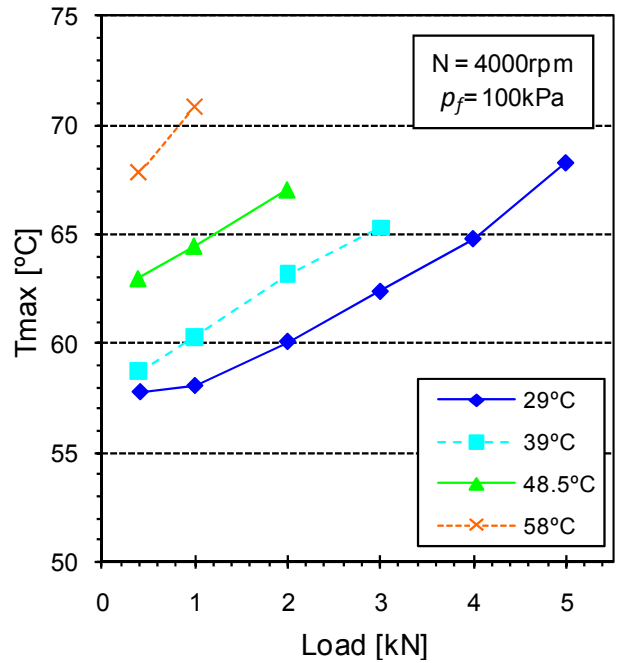

(a)

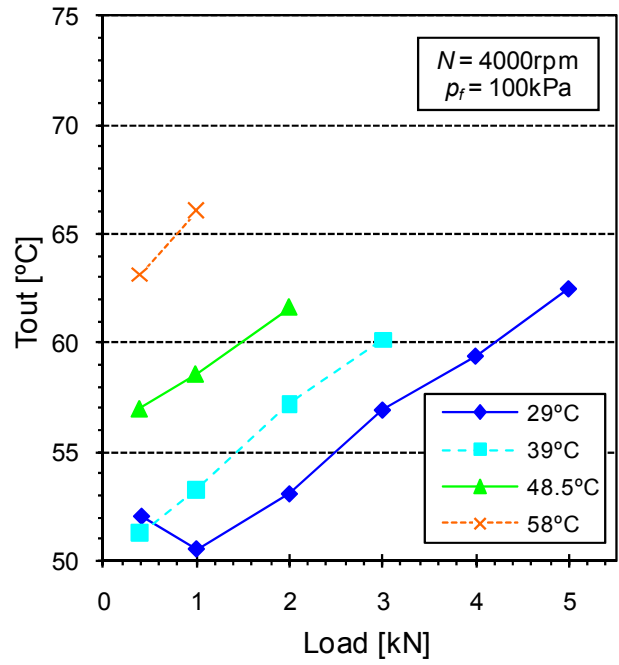

(b)

It is interesting to note in the lowest load tests [0.4 kN - Figure 7(a)] that the temperature profile corresponding to the lowest $T_{f}\left(29^{\circ} \mathrm{C}\right)$ is very close to the temperature profile of the test with a $T_{f} 10^{\circ} \mathrm{C}$ higher $\left(39^{\circ} \mathrm{C}\right)$. Not only the maximum bush temperature difference is only $0.9^{\circ} \mathrm{C}$, as detailed in Figure $8(\mathrm{a})$, but also the lubricant outlet temperature for the lower $T_{f}$ test $\left(29^{\circ} \mathrm{C}\right)$ is actually slightly higher than that of the higher $T_{f}$ test $\left[39^{\circ} \mathrm{C}-\right.$ Figure $\left.8(\mathrm{~b})\right]$. This might have happened because the higher lubricant $T_{f}$ was eventually compensated by the increase of the flow rate. In fact, Figure 4 shows that when $T_{f}$ increased from $29^{\circ} \mathrm{C}$ to $39^{\circ} \mathrm{C}$ the flow rate increased $60 \%$ (from $0.141 / \mathrm{min}$ to $0.22 \mathrm{l} / \mathrm{min}$ ), the greatest increase recorded in the chart. This ultimately leads to a similar cooling effect for both tests.

Additionally, when $T_{f}$ increased there was an eccentricity increase [Figure 3(a)] and it is known that within the very low eccentricity range, an increase in eccentricity actually yields a general decrease on bearing temperature. 
A temperature decrease with increasing eccentricity in the low eccentricity range was observed, for instance, with the tests carried out with bearing B2V1 under variable load, whose results are displayed in Figure 9. It can be seen that there was a decrease of Tmax when increasing the load (and therefore eccentricity) from $0.4 \mathrm{kN}$ to $1 \mathrm{kN}$ in the lowest $T_{f}$ tests. Inclusively, Tmax is highest for the lowest load in tests with $T_{f}=29.5^{\circ} \mathrm{C}$ and $\mathrm{N}=4,000 \mathrm{rpm}$ [Figures 9(b), 9(d)].

Figure 9 Temperature profile at the midplane of the inner bush surface for different loads and two different $T_{f}$ for (a) $\mathrm{N}=2,000 \mathrm{rpm}$ (b) 4,000 rpm. Influence of $T_{f}$ on maximum bush temperature and lubricant outlet temperature for (c) 2,000 rpm (d) 4,000 rpm (bearing $\mathrm{B} 2 \mathrm{~V} 1, p_{f}=100 \mathrm{kPa}$ ) (see online version for colours)

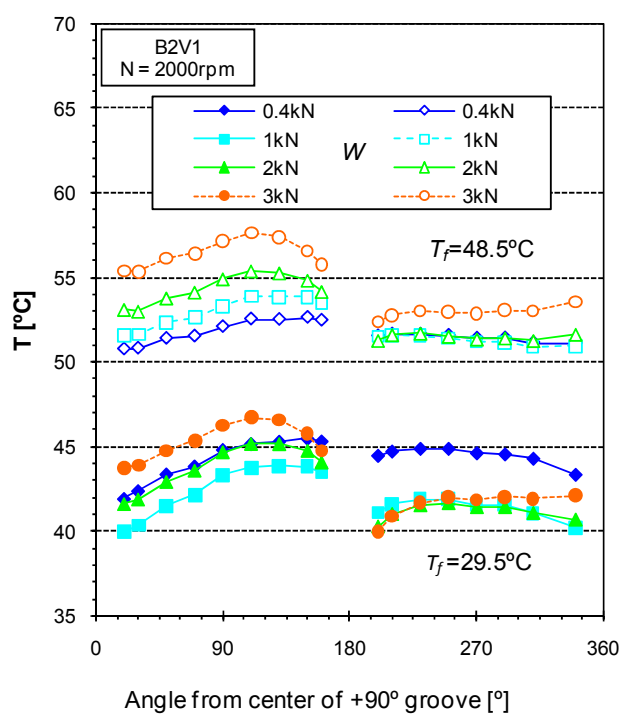

(a)

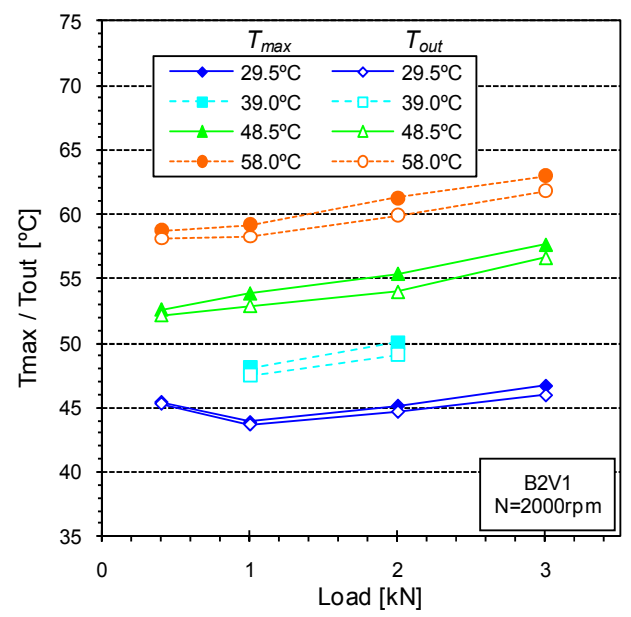

(c)

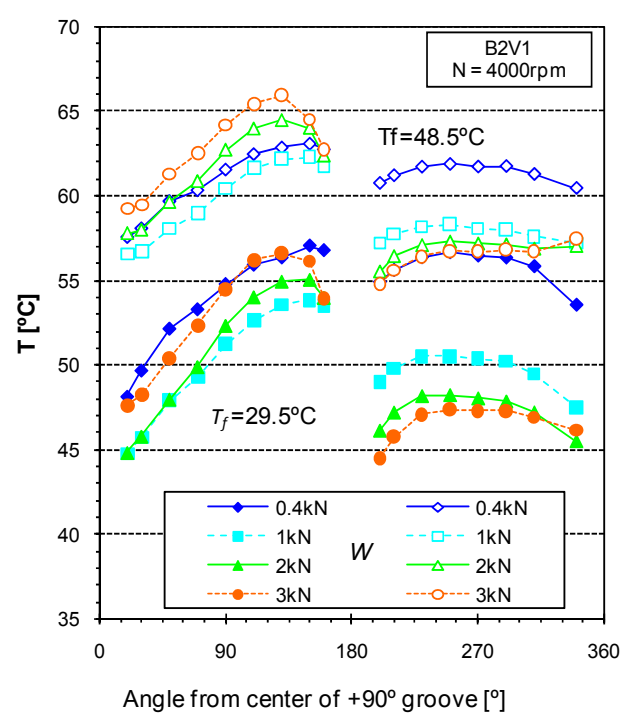

(b)

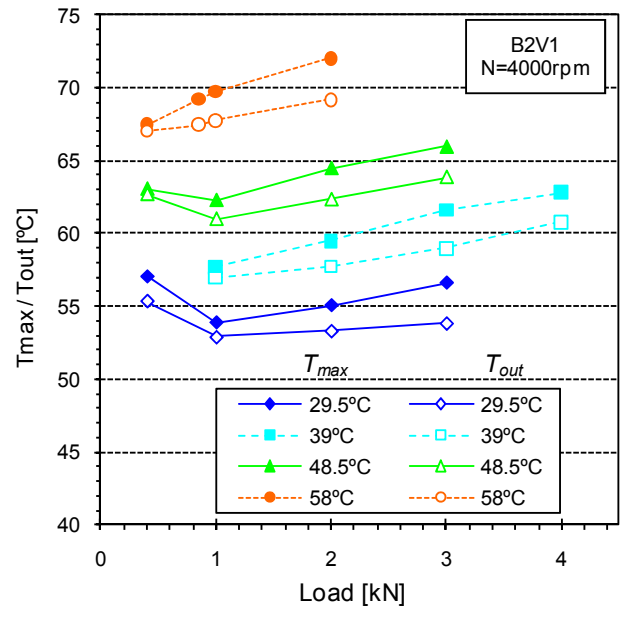

(d) 
By inspecting Figure 9, it can be seen that, for the same load, the increase of $T_{f}$ globally increased the temperature level, with this temperature increase being more pronounced at the loaded land of the bearing than at the unloaded land. Again, it can be said that the increase of $T_{f}$ has an effect on the trend of the temperature profiles which is comparable to the effect of load increase and to the effect speed decrease, which is linked to the increase of eccentricity usually observed in all of these situations.

\section{Conclusions}

An experimental assessment of the influence of lubricant $T_{f}$ on the performance of a $50 \mathrm{~mm}$ journal bearing with two axial grooves located at $\pm 90^{\circ}$ to the load line has been undertaken. Several loads (from $0.4 \mathrm{kN}$ to $5 \mathrm{kN}$ ), shaft speeds (2,000 rpm and 4,000 rpm) and bearing geometries were tested. The lubricant $p_{f}$ was kept constant at $100 \mathrm{kPa}$, while the $T_{f}$ took four different values $\left(29 / 29.5^{\circ} \mathrm{C}, 38.5^{\circ} \mathrm{C}, 48.5^{\circ} \mathrm{C}\right.$ and $\left.58^{\circ} \mathrm{C}\right)$.

Measurements of the temperature profiles at the oil-bush interface, oil outlet temperature, shaft locus and oil flow rate through each groove were performed. The individual measurement of the flow rate at each feed groove has seldom been performed on multi-grooved bearings. The knowledge of this information allowed a much deeper insight of the phenomena taking place.

For the conditions tested, it was found that:

1 The increase in $T_{f}$ had an effect on bearing performance analogous in many ways to the effect of increasing load/eccentricity. In fact, the increase in $T_{f}$ generally yielded increases in eccentricity, lubricant flow rate, maximum bush temperature (Tmax) and oil outlet temperature (Tout).

2 The increase of lubricant flow rate with increasing $T_{f}$ was more pronounced in the lower eccentricity range (in some cases this parameter doubled for a two-fold increase in $T_{f}$ ). Within the higher eccentricity range, this increase was less pronounced and mainly due to the increase of the lubricant supplied to the inactive land of the bearing. Moreover, an actual decrease of the amount of lubricant supplied to the active land of the bearing occurred with the increase of $T_{f}$.

3 In general, the higher was $T_{f}$, the higher were Tmax and Tout, although the increase of these parameters was always smaller than the corresponding increase in $T_{f}$. However, within the ranges of small eccentricity and low $T_{f}$, the effect of the increase in $T_{f}$ was compensated by the corresponding increase in flow rate, which kept nearly unchanged the global temperature level under such conditions.

This study points out to the overall conclusion that under lightly loaded conditions a moderate increase of $T_{f}$ might indeed prove beneficial in terms of reducing the power loss without compromising the safe operation of the system. In fact, although this parameter was not measured, it is known to decrease with increasing $T_{f}$ at mild loads due to the lowering of lubricant viscosity. However, the effect of $T_{f}$ would clearly not be beneficial in the case of heavily loaded bearings. Not only is it not guaranteed that any actual reduction in power loss would be obtained with the increase of $T_{f}$ (due to eccentricity increase), but also the risk of seizure would be greatly amplified.

The individualised measurement of the flow rate, which allowed the detection of rather dissimilar flow rates at each groove (that could even reach negative values in one 
of them), showed that lubrication effectiveness might not be as good as the value of the total flow rate would suggest. The increase of $T_{f}$ under such conditions would lower the critical load at which seizure is likely to occur.

\section{Acknowledgements}

The present work was supported by the PhD grant SFRH/BD/22278/2005 (financed by FCT POPH - QREN, the European Social Fund and MCTES) and by the project POCTI/39202/EME/2001 funded by FCT - Fundação para a Ciência e a Tecnologia (Portugal) and the European Union fund FEDER. The work has been carried out at the Tribology Laboratory of Minho University. The authors greatly acknowledge the support of these institutions.

\section{References}

Brito, F.P., Bouyer, J., Fillon, M. and Miranda, A.S. (2006) 'Thermal behaviour and performance characteristics of a twin axial groove journal bearing as a function of applied load and oil supply temperature', Tribologia - Finnish Journal of Tribology, The Finnish Society for Tribology, Vol. 25, No. 3, pp.24-33.

Brito, F.P., Miranda, A.S., Bouyer, J. and Fillon, M. (2007a) 'Experimental investigation of the influence of supply temperature and supply pressure on the performance of a two axial groove hydrodynamic journal bearing', ASME Journal of Tribology, Vol. 129, No. 1, pp.98-105.

Brito, F.P., Miranda, A.S., Pimenta Claro, J.C. and Fillon, M. (2007b) 'The role of each groove on the behaviour of twin axial groove journal bearings', IBERTRIB - Congreso Ibérico de Tribología, Escuela de Ingenieros, Bilbau, 20-21 June, CD-ROM.

Brito, F.P., Miranda, A.S., Pimenta Claro, J.C. and Fillon, M. (2008) 'Experimental study of the influence of groove flow rate on the performance of a single and a twin groove journal bearing', STLE Annual Meeting, May, pp.18-22, Cleveland, Ohio.

Claro, J.C.P. and Miranda, A.S. (1993) 'Analysis of hydrodynamic journal bearings considering lubricant supply conditions', Proc. Inst. Mech. Engs., Part C, Vol. 207, pp.93-101.

Costa, L., Miranda, A.S., Fillon, M. and Claro, J.C.P. (2003a) 'An analysis of the influence of oil supply conditions on the thermohydrodynamic performance of a single groove journal bearing', Proc. Inst. Mech. Engs., Part J: Journal of Engineering Tribology, Vol. 217, No. 2, pp.133-144.

Costa, L., Miranda, A.S., Claro, J.C.P. and Fillon, M. (2003b) 'Temperature, flow, and eccentricity measurements in a journal bearing with a single axial groove at $90^{\circ}$ to the load line', Lubrication Science, Vol. 15, No. 2, pp.147-161.

Ma, M.T. and Taylor, C.M. (1995) 'Effects of oil feed temperature on the performance of an elliptical bore bearing', Lubricants and Lubrication - Proc. of the 21st Leeds-Lyon Symposium on Tribology, Elsevier, pp.143-151.

Mitsui, J., Hori, Y. and Tanaka, M. (1983) 'Thermohydrodynamic analysis of cooling effect of supply oil in circular journal bearings', ASME Journal of Tribology, Vol. 105, No. 3, pp.414-421. 